\title{
Switching from Premixed Human Insulin to Premixed Insulin Lispro: A Prospective Study Comparing the Effects on Glucose Control and Quality of Life
}

\author{
Satoru Yamada ${ }^{1}$, Mari Watanabe ${ }^{2}$, Akira Kitaoka ${ }^{2}$, Kaoru Shiono $^{2}$, Koichiro Atsuda ${ }^{2}$, \\ Youko Tsukamoto $^{3}$, Yukiko Kawana ${ }^{3}$ and Junichiro Irie ${ }^{1}$
}

\begin{abstract}
Aim To evaluate the clinical effects of switching from premixed human insulin to a premixed rapid-acting insulin analogue in type 2 diabetic patients.

Research Design and Methods Thirty patients, who were treated with a twice-daily injection of premixed human insulin, were enrolled and randomized to (i) 50/50 premixed insulin lispro twice-daily at the same daily dose as premixed human insulin (analogue mix group), or (ii) continued premixed human insulin (control group). The doses of insulin were adjusted every month by registered diabetologists to achieve adequate blood glucose levels. At the beginning of the study, and again 4 months later, $\mathrm{HbA}_{\mathrm{lc}}$ and blood glucose levels were measured, and the amount of insulin required and BMI were recorded in both groups. Insulin therapyrelated quality of life (ITR-QOL) and the diabetes treatment satisfaction questionnaire (DTSQ) were also assessed in the analogue mix group at the beginning of the study and again 4 months later.

Results Although $\mathrm{HbA}_{1 \mathrm{c}}$ levels did not change significantly over the duration of the study in the control group $(7.33 \pm 0.58$ vs $7.29 \pm 0.65 \%), \mathrm{HbA}_{\mathrm{lc}}$ did improve significantly in the analogue mix group (7.59 \pm 0.44 vs $7.24 \pm 0.49 \% ; \mathrm{p}<0.05)$. The dose of insulin required in the analogue mix group did not change significantly $(0.37 \pm 0.11 \mathrm{vs} 0.38 \pm 0.14 \mathrm{U} / \mathrm{kg} /$ day $)$, but increased in the control group from $0.34 \pm 0.15$ to 0.37 $\pm 0.16 \mathrm{U} / \mathrm{kg} /$ day $(\mathrm{p}<0.05)$. The switch to the premixed insulin analogue did not affect ITR-QOL and DTSQ scores.

Conclusions This study showed that switching from premixed human insulin to 50/50 premixed insulin lispro improved blood glucose control without compromising QOL. This finding suggests that a premixed rapid-acting insulin analogue is more effective than human insulin for Japanese type 2 diabetic patients.
\end{abstract}

Key words: insulin analogue, glycemic control, quality-of-life

(DOI: 10.2169/internalmedicine.46.0236)

\section{Introduction}

The goals of the treatment of diabetes mellitus are to prevent diabetes-related complications, to maintain quality of life (QOL), and to maintain a duration of life similar to that of healthy individuals. In order to achieve these goals, blood glucose levels need to be well controlled (1-3). In particular, the control of postprandial hyperglycemia has been emphasized because postprandial glucose has been reported to be associated with cardiovascular complications (4-6).

Intensive insulin therapy is ideal for improving glycemic control, but many type 2 diabetic patients prefer fewer injections to multiple injections. A single daily injection of a long-acting insulin analogue or a twice-daily injection of intermediate-acting insulin is widely used for the treatment of type 2 diabetes (7). Since long-acting insulin analogues or intermediate-acting insulin alone cannot prevent postprandial hyperglycemia, premixed insulin (made of a combination of short- or rapid-acting insulin and intermediate-acting

${ }^{1}$ Department of Internal Medicine, Kitasato Institute Hospital, Tokyo, ${ }^{2}$ School of Pharmaceutical Sciences, Kitasato University, Tokyo and ${ }^{3}$ Department of Nursing, Kitasato Institute Hospital, Tokyo

Received for publication April 17, 2007; Accepted for publication June 25, 2007

Correspondence to Dr. Satoru Yamada, yamada-s@kitasato.or.jp 
insulin) was developed. Currently, 70/30 and 50/50 premixed human insulin preparations are mainly used. Recently, premixed insulin preparations with rapid-acting insulin analogues have been developed to control both pre- and postprandial hyperglycemia while still preventing hypoglycemia.

Theoretically, rapid-acting insulin analogues should be more effective for preventing postprandial hyperglycemia associated with higher glycemic-index foods than short-acting human (regular) insulin. Since East-Asians prefer foods with a higher glycemic index, such as rice, than Caucasians, premixed insulin preparations with rapid-acting insulin analogues should have beneficial effects on glycemic control in East-Asian patients with diabetes. However, our previous study did not show a beneficial effect on the glycohemoglobin level with premixed rapid-acting insulin analogues compared with premixed human insulin in insulin-naive patients with diabetes (8). Thus, we speculated that a small proportion of insulin analogues, i.e. $30 \%$, is not sufficient to prevent postprandial hyperglycemia, necessary to attain greater improvements in glycohemoglobin.

Therefore, in the present study, we evaluated the clinical effectiveness of a 50/50 premixed rapid-acting insulin analogue compared with a 70/30 or 50/50 premixed human insulin preparation in Japanese patients with diabetes.

\section{Materials and Methods}

\section{Study design}

In this open-label, prospective, randomized trial, 30 patients with type 2 diabetes who visited Kitasato Institute Hospital between June and July 2005 were enrolled. The criteria for enrollment were: 1) treatment with a twice-daily injection of 70/30 or 50/50 premixed human insulin for at least 3 months, and 2) $\mathrm{HbA}_{\mathrm{lc}}$ levels $>6.5 \%$. Patients who were anti-glutamic acid decarboxylase (GAD) antibodypositive were excluded regardless of whether or not they were non-insulin dependent, as were those with proteinuria $>1.0 \mathrm{~g} /$ day, serum creatinine $>1.5 \mathrm{mg} / \mathrm{dL}$ (men) or $1.2 \mathrm{mg} / \mathrm{dL}$ (women), abnormal aspartate aminotransferase (AST)/ alanine aminotransferase (ALT) elevation ( $>3$ times the upper limit of normal), proliferative retinopathy, myocardial infarction or stroke within 6 months prior to study entry, and severe hypertension [systolic blood pressure (SBP)/diastolic blood pressure (DBP) $>180 / 100 \mathrm{mmHg}$. All patients received an explanation of the procedures to be performed and of possible disadvantages that may arise from the study; they then gave their written informed consent to participate. This study was performed in accordance with the Declaration of Helsinki and was approved by our institutional review board.

The patients were randomly divided, using a permuted randomized block by computer, into two groups: 1) analogue mix group and 2) control group. In the analogue mix group, the patients began using a 50/50 premixed insulin
Table 1. Patient Characteristics at The Start of The Study

\begin{tabular}{|l|c|c|c|}
\hline & Mix 50 & Control & p-value \\
\hline No. of patients (men/women) & $15(12 / 3)$ & $15(11 / 4)$ & - \\
\hline Age (years) & $66.0 \pm 10.2$ & $66.3 \pm 10.3$ & n.s. \\
\hline Duration of disease (years) & $13.7 \pm 7.7$ & $15.9 \pm 9.3$ & n.s. \\
\hline HbA $(\%)$ & $7.59 \pm 0.44$ & $7.33 \pm 0.58$ & n.s. \\
\hline Fasting blood glucose (mg/dL) & $130.3 \pm 50.7$ & $141.8 \pm 51.9$ & n.s. \\
\hline Insulin dose (U//kg/day) & $0.37 \pm 0.11$ & $0.34 \pm 0.15$ & n.s. \\
\hline Body mass index (kg/m²) & $27.0 \pm 5.8$ & $23.8 \pm 3.4$ & n.s. \\
\hline
\end{tabular}

Mean \pm standard deviation, $\mathrm{p}$-value by Student's t-test

analogue (lispro) twice daily at the same daily dose as their current insulin preparation. In the control group, the patients continued to use the premixed human insulin preparation. The doses of insulin were adjusted every month in both groups by registered diabetologists in order to achieve adequate blood glucose control, with clinic-measured postprandial glucose $<180 \mathrm{mg} / \mathrm{dL}$ and self-monitored fasting blood glucose $<130 \mathrm{mg} / \mathrm{dL}$. At the start of the study and again 4 months later, $\mathrm{HbA}_{\mathrm{lc}}$ and fasting blood glucose levels were measured and the amount of insulin required, body mass index (BMI), and blood pressure were recorded. Insulin therapy-related quality-of-life (ITR-QOL) (9) and the diabetes treatment satisfaction questionnaire (DTSQ) (10) were assessed at the start of the study and again 4 months later. ITR-QOL was specifically designed to assess the influence of insulin therapy on QOL. In this questionnaire, 23 items broadly related to present status (social activities, 5 items; physical function, 4 items; daily activities, 3 items) and therapy-related feeling (11 items) are each rated on a Likert scale of 1 (poor) to 5 (good) to give a maximum QOL score of 115 .

\section{Statistical analyses}

A last-observation-carried-forward analysis was performed. Differences between the groups in $\mathrm{HbA}_{1 \mathrm{c}}$ and blood glucose levels, insulin doses and BMI were tested using an unpaired t-test. Differences between values at the start of the study and at 4 months were tested using a paired t-test. All data are presented as means \pm standard deviation. The differences in ITR-QOL and DTSQ results between the two groups were tested using a Wilcoxon signed rank test. A p value of $<0.05$ was recognized as significant.

\section{Results}

Patient characteristics at the start of the study are presented in Table 1; there were no significant differences be- 
Table 2. Changes in Glycemic Indices, the Dose of Insulin Required and BMI

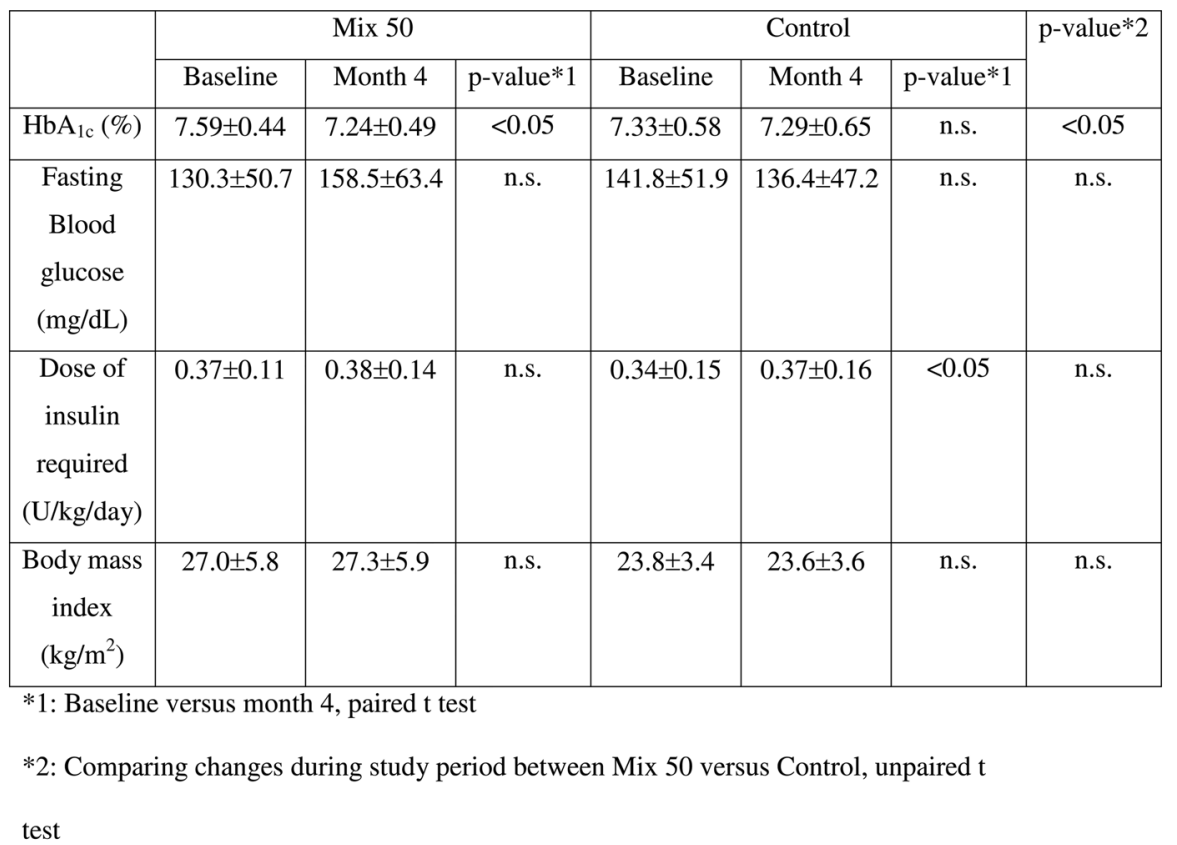

tween the two groups. In both groups, 13 patients were receiving 70/30 premixed human insulin preparation and two patients $50 / 50$ premixed human insulin preparation at the start of the study.

At 4 months, hyperglycemia was significantly improved in the analogue mix group (mean $\mathrm{HbA}_{\mathrm{lc}}$ was $7.59 \pm 0.44 \%$ at the start of the study and $7.24 \pm 0.49 \%$ at 4 months, $\mathrm{p}<$ $0.05)$, whereas no improvement was observed in the control group (mean $\mathrm{HbA}_{\mathrm{lc}}$ was $7.33 \pm 0.58 \%$ at the start of the study and $7.29 \pm 0.65 \%$ at 4 months). Fasting blood glucose levels were not improved at 4 months in either group (Table 2).

The mean dose of insulin required in the analogue mix group did not change over 4 months (from $0.37 \pm 0.11 \mathrm{U} /$ $\mathrm{kg} /$ day at the start of the study to $0.38 \pm 0.14 \mathrm{U} / \mathrm{kg} /$ day at 4 months), whereas it increased in the control group (from $0.34 \pm 0.15 \mathrm{U} / \mathrm{kg} /$ day to $0.37 \pm 0.16 \mathrm{U} / \mathrm{kg} /$ day; $\mathrm{p}<0.05)$. The BMI values did not change over 4 months in either group (Table 2).

In terms of quality of life, both the ITR-QOL score and DTSQ did not change over 4 months in the analogue mix group (Table 3). Interestingly, however, the value for convenience (as measured by DTSQ) improved from 3.8 to 4.8 $(\mathrm{p}<0.05)$ after switching to premixed insulin lispro. No adverse events, including severe hypoglycemia, which requires assistance from other people to recover, occurred during the study.

\section{Discussion}

In this randomized study, we showed a significant improvement in $\mathrm{HbA}_{\mathrm{lc}}$ levels using premixed insulin lispro instead of premixed human insulin. Because 50/50 premixed insulin lispro is known to control postprandial glucose better than $75 / 25$ premixed insulin lispro (11) and fasting plasma glucose did not change in this study, it seems likely that the improvement in $\mathrm{HbA}_{1 \mathrm{c}}$ was due to the reduction in postprandial glucose.

There seem to be three reasons why premixed insulin lispro improved glycemic control in this study. One is that the study subjects are Japanese. There have been several conflicting reports regarding the effectiveness of twice-daily injections of premixed rapid-acting insulin analogues or rapidacting insulin analogue together with neutral protamine Hagedorn (NPH) insulin on glycemic control $(8,12-15)$. One non-randomized study showed an improvement in $\mathrm{HbA}_{\mathrm{cc}}$ levels in Japanese patients (12), while the other randomized studies showed no difference in $\mathrm{HbA}_{\mathrm{lc}}$ levels in Japanese (8), Canadian (13), American (14) and European (15) patients. Theoretically, a greater proportion of rapidacting insulin analogues would be more effective for higher glycemic-index foods; therefore, since Japanese typically consume higher glycemic-index foods, such as rice, than Caucasians, this might explain the limited effectiveness of the rapid-acting insulin analogue together with $\mathrm{NPH}$ insulin or premixed rapid-acting insulin analogues in Caucasian patients (13-15). Second is the study design. In previous studies, insulin-naïve patients have not shown greater improvements in glycemic control with rapid-acting insulin analogue(s) (13) even in Japanese patients (8). Either insulin analogues or human insulin could improve glycemic control greater for insulin-naïve patients. However, the differences in glycemic control between these two preparations might be small and difficult to detect. Third is the proportion of insulin analogues. Previous switching designed studies, which showed no effect on glycohemoglobin, examined the effect of $25 \%$ (14) or $30 \%$ (15) mixtures of rapid-acting insulin analogues. As in our hypothesis, we speculated that 25 
Table 3. The Insulin Therapy-Related Quality-of-Life (ITR-QOL) Score and Diabetes-Treatment-Satisfaction-Questionnaire (DTSQ) Score

\begin{tabular}{|c|c|c|c|}
\hline ITR-QOL & Baseline & Month 4 & p-value \\
\hline $\begin{array}{l}\text { Present Status } \\
\text { (questions 1-12) }\end{array}$ & $53.27 \pm 5.38$ & $52.93 \pm 5.96$ & n.s. \\
\hline $\begin{array}{l}\text { Social activities } \\
\text { (questions 3, 4, 5, } 10 \text { and } \\
\text { 11) }\end{array}$ & $22.33 \pm 3.52$ & $22.20 \pm 3.21$ & n.s. \\
\hline $\begin{array}{l}\text { Physical function } \\
\text { (questions 6, 7,9 and 12) }\end{array}$ & $18.07 \pm 2.52$ & $17.60 \pm 2.29$ & n.s. \\
\hline $\begin{array}{l}\text { Daily activities } \\
\text { (questions 1,2 and 8) }\end{array}$ & $12.87 \pm 1.92$ & $13.13 \pm 1.96$ & n.s. \\
\hline $\begin{array}{l}\text { Therapy-related feeling } \\
\text { (questions 13-23) }\end{array}$ & $44.60 \pm 7.94$ & $46.53 \pm 6.86$ & n.s. \\
\hline $\begin{array}{l}\text { Total scale } \\
\text { (questions 1-23) }\end{array}$ & $97.87 \pm 12.72$ & $99.47 \pm 12.32$ & n.s. \\
\hline \multicolumn{4}{|l|}{ DTSQ } \\
\hline Treatment Satisfaction & $23.48 \pm 7.63$ & $25.08 \pm 6.16$ & n.s. \\
\hline Hyperglycemia (question 2) & $3.52 \pm 1.92$ & $4.76 \pm 1.83$ & n.s. \\
\hline Hypoglycemia (question 3) & $1.52 \pm 1.58$ & $1.72 \pm 1.95$ & n.s. \\
\hline
\end{tabular}

Mean \pm standard deviation, $\mathrm{p}$-value by Wilcoxon's signed rank test

or $30 \%$ mixtures are not sufficient to prevent postprandial hyperglycemia.

Although the present study did not show that the administration of premixed insulin lispro was more effective to improve QOL or treatment satisfaction, improvements in glycemic control without compromising QOL or treatment satisfaction are beneficial for diabetic patients. As for QOL, the ITR-QOL in the premixed insulin analogue group was higher in our previous study using the same insulin injector as the control group (8). Therefore, the change in insulin injector might have affected QOL in this study.

In conclusion, our randomized study showed that 50/50 premixed insulin lispro improved blood glucose control without compromising QOL compared with premixed human insulin. Since this study was open label with a small number of patients, further studies, which are larger and/or longer, are necessary to confirm the effectiveness of premixed insulin analogues.

\section{References}

1. The Diabetes Control and Complications Trial Research Group The effect of intensive treatment of diabetes on the development and progression of long-term complications in insulin-dependent diabetes mellitus. N Engl J Med 329: 977-986, 1993.

2. U.K. Prospective Diabetes Study (UKPDS) group. Intensive blood glucose control with sulphonylureas or insulin compared with conventional treatment and risk of complications in patients with type 2 diabetes (UKPDS33). Lancet 352: 837-853, 1998.

3. Ohkubo Y, Kishikawa H, Araki E, et al. Intensive insulin therapy prevents the progression of diabetic microvascular complications in Japanese patients with non-insulin-dependent diabetes mellitus: a randomized prospective 6-year study. Diabetes Res Clin Pract 28: 103-117, 1995.

4. DECODE Study Group. Glucose tolerance and mortality: comparison of WHO and American Diabetic Association diagnostic criteria. Lancet 354: 617-621, 1999.
5. Nakagami T, DECODA Study Group. Hyperglycaemia and mortality from all causes and from cardiovascular disease in five populations of Asian origin. Diabetologia 47: 385-394, 2004.

6. Tominaga M, Eguchi $\mathrm{H}$, Nakata $\mathrm{H}$, et al. Impaired glucose tolerance is a risk factor for cardiovascular disease, but not impaired fasting glucose: the Funagata Diabetes Study. Diabetes Care 22: 920-924, 1999.

7. Hirsch IB, Bergenstal RM, Parkin CG, et al. A real-world approach to insulin therapy in primary care practice. Clinical Diabetes 23: 78-86, 2005.

8. Yamada S, Tamada T, Watanabe M, et al. Comparison of biphasic insulin aspart 30/70 and premixed human insulin 30/70: Glycemic control and quality of life in insulin-naïve type 2 diabetic patients. Clinical Practice 26: 58-64, 2007.

9. Ishii H, Yamamoto T, Ohashi Y. Development of insulin therapy related quality of life measure (ITR-QOL). J Jpn Diabetes Soc 44: 
9-15, 2001 (in Japanese).

10. Bradley C. Diabetes treatment satisfaction questionnaire (DTSQ). In: Handbook of Psychology and Diabetes. Bradley C, Ed. Harwood Academic Publishers, 1994. Chur. P111-132.

11. Roach $\mathrm{P}$, Arora V, Campaigne BN, et al. Humalog Mix50 before carbohydrate-rich meals in type 2 diabetes mellitus. Diabetes Obes Metab 5: 311-316, 2003.

12. Iwamoto $Y$, Kawamori R, Kadowaki T, Akanuma Y, Beattie SD, Malone JK. Clinical study of insulin lispro mixture-25 and mixture 50 administered twice daily in insulin-requiring patients with type 1 and type 2 diabetes mellitus. Rinsho Iyaku 18: 395-409, 2002 (in Japanese).
13. Ross SA, Zinman B, Campos RV, Strack T, Canadian Lispro Study Group. A comparative study of insulin lispro and human regular insulin in patients with type 2 diabetes mellitus and secondary failure of oral hypoglycemic agents. Clin Invest Med 24: 292-298, 2001.

14. Roach P, Yue L, Arora V, The Humalog Mix25 Study Group. Improved postprandial glycemic control during treatment with Humalog Mix25, a novel protamine-based insulin lispro formulation. Diabetes Care 22: 1258-1261, 1999.

15. Boehm BO, Home PD, Behrendt C, Kampt NM, Lidholmt A. Premixed insulin aspart 30/70 twice daily: a randomized trial in type 1 and type 2 diabetic patients. Diabet Med 19: 393-399, 2002.

(C) 2007 The Japanese Society of Internal Medicine http://www.naika.or.jp/imindex.html 